The second option is to support in-country training; ODA for example is setting up research fellowships in the developing world.

A third option, which would lead to a more fertile exchange of ideas and moreover increase awareness of cross-cultural and global issues in Western psychiatrists, is to set up secondment schemes between centres. Postgraduate psychiatrists (senior registrar level in UK) could contribute to training, boost manpower and morale, and with backing from their home base facilitate research. A three year secondment would be the minimum on account of the adaptation required. In return, developing country psychiatrists might find overseas experience more meaningful after basic training in their relevant environment. WHO, ODA and the Commonwealth Secretariat have expressed an interest in such schemes.

The Maudsley Hospital

E. A. GuINNESS

London SE5 $8 A Z$

Institute of Psychiatry

Raj Persaud

London SE5 8 AF

\section{Psychiatry and philosophy}

DeAR Sirs

Morris's statement (Psychiatric Bulletin, May 1992, 16, 294-295) that the two opposing theoretical positions in psychiatry (the psychodynamic and the biological) "are part of a fundamental debate running through the history of philosophy, between the traditions in the philosophy of metaphysics of materialism and idealism" is a dogmatic assertion, unsupported by evidence or argument. There are no conceptual or historical connections between these two positions and the debates surrounding the idealism/realism issue in the history of philosophy. The practice of clinical psychiatry is based upon acceptance of the existence of such phenomena as mental processes, psycho-social structures, cerebral pathology and neuro-chemical changes. The clinician or research worker adopts the stance characterised by the philosopher as 'common-sense realism'. Philosophical reflection upon this basic position/ 'experience of the world' can complicate matters by showing that its ultimate analysis can lead to the philosophical theses of either metaphysical idealism or metaphysical realism. Thus, common-sense realism can not only be extended (by philosophical considerations) to a form of metaphysical realism (or naturalism or materialism) but shown to be fully compatible with metaphysical idealism (Acton, 1967).

Philosophical idealism of the traditional variety has no serious adherents in contemporary philosophy. Many different kinds of realism compete today in the philosophical marketplace: the 'scientific realism' of many philosophers of science, the
'Realism with a Human Face' of Hilary Putnam and the 'transcendental realism' of phenomenologists.

The most serious lacuna in Morris's account is the failure to mention the major philosophical school of phenomenology. Its two divergent manifestations the 'transcendental phenomenology' of Husserl and the 'fundamental ontology' of Heidegger - are based on a fundamental conviction and claim to have definitively overcome the ages-old dichotomy of idealism/ realism-this is the source of their philosophical interest. Philosophical phenomenology has had a decisive impact on the theory and practice of psychiatry, psychology and psychotherapy on the European continent and North America but only marginally so in Britain.

In their extreme forms the two opposed views (psychodynamic and biological) are related to the central issue of whether the focus is on human beings as persons or as (biological) organisms. Although this conceptual polarity is deeply embedded in our modern 'scientific' culture, I do not think it is related to the idealism/realism debate, rather a reflection of tendencies and thought-patterns which have been developing in our culture over the past three hundred years. The exploration of these issues has now become a matter of urgent importance.

\section{Salman Rashid}

\section{The Royal Oldham}

Hospital Trust

Oldham OL1 $2 \mathrm{JH}$

\section{Reference}

Acton, H. B. (1967) Idealism, The Encyclopaedia of Philosophy London: Collier-Macmillan. Volume 4, pp 110-118.

\section{Reply}

\section{DEAR SIRS}

I welcome with interest Dr Raschid's contribution, in particular his clarification of "materialism" as a type of philosophical realism. I think we are fundamentally in agreement, that there is a conceptual polarity in psychiatry the patient being a "person" or an "organism". I believe that the philosophical expression of these cultural thought patterns is the idealist/realist debate; another incarnation is the mind/body debate. Dr Raschid disagrees, although he does not argue this position.

Phenomenology argues that it is only those things that are directly available to experience that can be studied. Sadly for biological psychiatry, however, this rules out such notions as dopamine receptors and monoamine reuptake inhibitors. There is nothing in a phenomenological metaphysic to decide whether the "Dasein" (being-in-the-world) of the patient who believes the CIA control his brain is any more or less valid than the "Dasein" of the psychiatrist who believes 
he is deluded. A phenomenological approach to psychiatry examines the experiences of the "person", but has nothing to say regarding how one marries these to scientific observations of the "organism".

There is a (probably apocryphal) story of a 17th century debate ending with the realist challenging the idealist to stop eating and drinking substances in the outside world which he did not believe existed. In the same way, an appeal to common-sense realism finishes the argument without really furthering it.

1 Lynton Road

MARK MORRIS

London N6 6BD

\section{Bulgarian Psychiatric Association}

DEAR SIRS

The Constituent Assembly of the new Bulgarian Psychiatric Association (BPA) took place in May. The BPA is an independent non-profit-making professional organisation which is registered under Bulgarian law with its head office in Sofia.

The programme adopted as a priority for its first year a critical review of the current state of psychiatry in Bulgaria, with an emphasis on human rights issues. This is perceived as essential to recover the integrity and values of the profession following their abuse under the previous political regime. In undertaking this task, the BPA will clearly benefit from experience and technical assistance from other national or international associations, especially regarding the following issues.

(a) Sensitisation, dissemination of knowledge and technical expertise leading to "good practices" in the professional training and development of psychiatrists.

(b) Reconciling the individual liberties and rights of mental patients with unhindered access to treatment when needed (for example, many services at present avoid dealing with psychiatric emergencies for fear of allegations of psychiatric abuse).

(c) Development of an appropriate and valid procedure for investigating complaints and claims of psychiatric abuse or human rights violations.

We do hope that the British psychiatric community will extend its cooperation to the BPA and assist us in attaining the goals we have set for ourselves in this first year of the organisation's existence.

Tома TомоV

President-Elect

Bulgarian Psychiatric Association

15 D. Nestorov Str.,

1431 Sofia, Bulgaria

\section{East European Medical Journal}

\section{DeAr Sirs}

Starting in August 1992, we intend to establish a new medical journal East European Medical Journal, conceived as a peer-reviewed scientific publication focusing on specific medical aspects in East and Central Europe and to be published in English.

We feel that the unidirectional flow of the best scientific papers towards Western journals represents a danger for local cultural experience. One of the keys to educational, social and cultural development could be high quality journals that create opportunities for self expression of local scientists and for developing a sense of regional unity and historic tradition. These publications could play a significant role in pushing people to compete and creating new leaders. Creating a new elitism in our society and supporting it by a scientific culture becomes an important social claim.

It is about this development project that I approach you for help. We need to involve some Western colleagues in order to provide assistance in the editorial processing of manuscripts and we are looking for a large team of peer reviewers. Papers addressed to this journal will be welcome.

We thank you in advance and hope to receive comments and suggestions from your readers.

TRAIAN MihXESCU

East European Medical Journal

Editor

Eurocip, P.O. Box 209

Iasi 6600

Romania

\section{Visual arts in clinical settings}

\section{DeAr Sirs}

The visual arts are used or promoted by many professions within the health and social services. Perhaps some of your readers may be interested in contributing to a conference which aims to bring these professions together in order to present and discuss the different uses and understandings of the visual arts in clinical settings. More information can be obtained by ringing Pat Coopey on Gloucester (0452) 617033 extension 2359.

TED QuinN

Head Art Therapist

(Visual Arts Conference Co-ordinator)

Gloucestershire Health Authority

Coney Hill Hospital

Gloucester GL4 7QJ 